\title{
Effect of Vegetation on Air Pollutants Affecting the Health of the Fetus
}

\author{
Nahid Rezaei \\ Department of Industrial Engineering \\ Faculty of Engineering \\ Energy Institute of Higher Educations, Saveh, Iran
}

\author{
Taher Taherian \\ Department of Industrial Engineering \\ Faculty of Engineering \\ Energy Institute of Higher Educations, Saveh, Iran
}

\begin{abstract}
Today, air pollution is considered as one of the most complicated and critical issues influential in people's health to the extent that it is even sometimes regarded as a crisis in human societies. As it is known, developing urban green space is a way of reducing air pollution and on the other hand, destroying urban green space is highly influential in increasing air pollution and consequently in endangering people's health. In the present study, it has been tried to put forward some strategies for preserving and developing urban green space and also the role of selecting plants types in urban green cover has been investigated.
\end{abstract}

\section{General Terms}

Pollution, Health, Safety, Environment.

\section{Keywords}

Urban green area, HSE, Air Pollution.

\section{INTRODUCTION}

As it is known, today urban green space are of high strategic importance in improving living conditions. (12) Since green space are among the most important factors in the health condition of society's people, preserving and controlling urban green space can be very influential in boosting people's health. Studies suggest that at the present time, many cities in Iran lack enough green spaces or are faced with inappropriate dispersion which in turn brings about a decrease in the public health level. (13) Tehran, as one of Iranian cities is involved with this issue and due to the significance of the Greater Tehran metropolis in terms of population density and air pollution and its strategic importance as the capital of Iran; it has been chosen as the location of this research study.

Regina Grazuleviciene, 2015 [1] showed that there is a significant relationship between the distance of the green space to the residence place of pregnant women and their infants' weight at the time of the birth. Also, Sarah I. Bell, 2014 [2] indicated the relation between green space and public health level during the course of time. Moreover, Jennifer R. wolch (2014), [3] explained the effect of green space expanse on public spirits. Also, Payam Dadvand (2014), [4] showed the influence of pregnant women's residence proximity to green space on their infants' weight at the time of birth. In addition, the studies carried out by Elissa $\mathrm{H}$. (2014), [5] indicated the positive effect of green space on the life time duration of those with a stroke. Mazlina Mansor (2014), [6] in an international conference on quality of life revealed that there is a relation between non-communicable illnesses outbreaks such as mental stress and the proportion of green space. Nutsford D. (2013) [8] explained the role of green space on people's mental health. Furthermore, Studies conducted by Oliver T. Laurent et al., (2014) [7] suggested that being close to green space can positively affect infants' weight at the time of birth. Oliver T. Mytton et al., (2012) [9] showed that green space affects the highest level of public health. Payam Dadvand (2012), [10] for the second time showed the effect of pregnant women's residence proximity to green space on their infants' weight at the time of birth. Also, Paul J. Villeneuve (2012), [11] explained the influence of green space on mental serenity of people living in Canada.

\section{MODEL DESCRIPTION}

In order to conduct the present study, we needed to collect some data about Tehran in terms of the expansion and dispersion of green space in different districts of this city. The related data were gathered through referring to municipalities of different districts and also through Tehran Municipality's official website. It is also worth mentioning that by green space here we mean urban green space.

In the following you can see the characteristics of Tehran:

Tehran is located on a flat plain between Alborz Mountain range and the northern margin of Iran's Central Desert (Dasht-e kavir). From north it is surrounded by Alborz Mountain range and from south and south west by Rey and Bibishahrbanu Mountains. To the west of this city there is Karaj River and to its east there is another river called Jajrood River. A general look at Tehran and its boundaries: Before being chosen as the capital city of Iran by the Qajar Dynasty, Tehran was a small town which rapidly developed afterwards. Based on the census conducted in the year 2006 , this city had a population of 7756036 individuals. It is divided into 22 districts in which parks/city parks have been scattered disproportionate to the number of people 


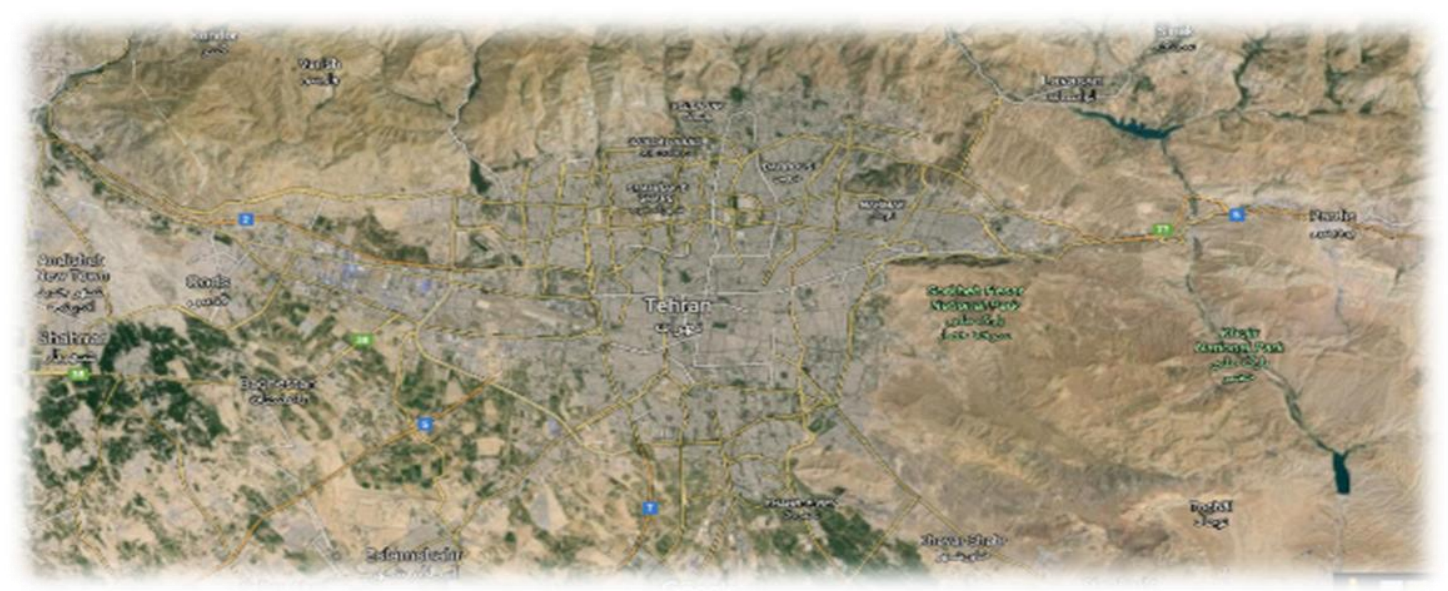

Fig 1. Over view of the city Tehran

In the following table you can find the information as to the number of parks in the different districts of Tehran.

Table 1. Numbers of park in each distraction

\begin{tabular}{|c|c|}
\hline The numbers of parks & Distractions \\
\hline 139 & distraction1 \\
\hline 154 & distraction 2 \\
\hline 86 & distraction 3 \\
\hline 218 & distraction 4 \\
\hline 187 & distraction 5 \\
\hline 166 & distraction6 \\
\hline 54 & distraction7 \\
\hline 78 & distraction 8 \\
\hline 25 & distraction 9 \\
\hline 47 & distraction 10 \\
\hline 29 & distraction 11 \\
\hline 56 & distraction 12 \\
\hline 70 & distraction 13 \\
\hline 72 & distraction 14 \\
\hline 103 & distraction 15 \\
\hline 53 & distraction 16 \\
\hline 53 & distraction 17 \\
\hline 82 & distraction 18 \\
\hline 61 & distraction 19 \\
\hline 136 & distraction 20 \\
\hline 40 & distraction 21 \\
\hline 64 & distraction 22 \\
\hline
\end{tabular}

As it is shown in the table, the highest numbers of parks are located in district 4 .

The distribution of the parks in proportion to the population of each district is different, i.e. in some districts of Tehran, the size and the numbers of parks have been distributed disproportionate to the number of population living in those districts. In table 2 you may see the mentioned fact.

Figure2, shows the number of parks available in each distriction.

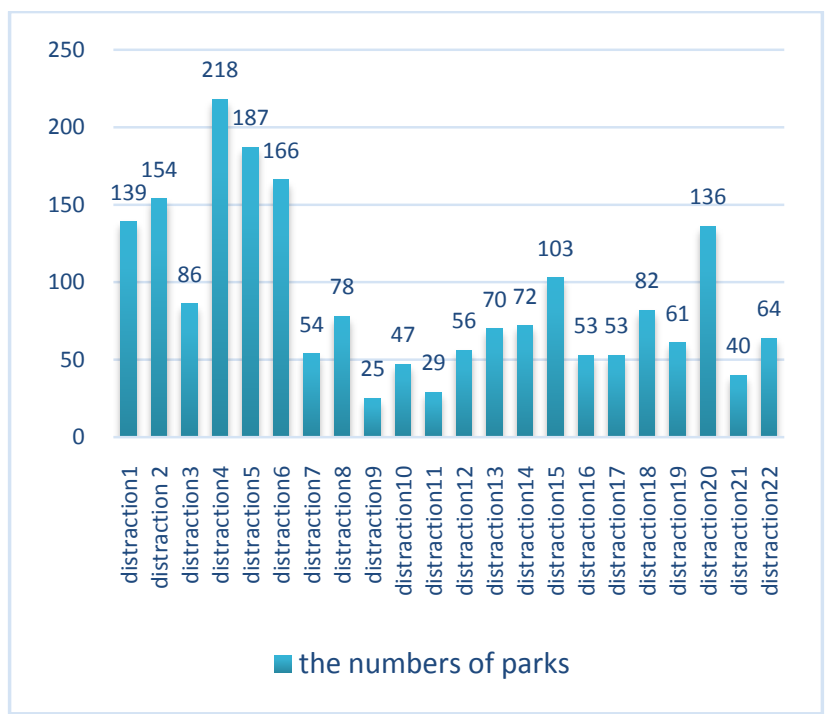

Fig 2. The numbers of park in each distraction

Table 2. Population index for every park

\begin{tabular}{|c|l|}
\hline $\begin{array}{c}\text { Population index for } \\
\text { every park }\end{array}$ & District \\
\hline 2852 & District 1 \\
\hline 4136 & District 2 \\
\hline 3791 & District 3 \\
\hline 4065 & District 4 \\
\hline 3812 & District 5 \\
\hline 3805 & District 6 \\
\hline 5990 & District 7 \\
\hline 5079 & District 8 \\
\hline
\end{tabular}




\begin{tabular}{|l|l|}
\hline 6658 & District 9 \\
\hline 7109 & District 10 \\
\hline 9957 & District 11 \\
\hline 4659 & District 12 \\
\hline 3840 & District 13 \\
\hline 7992 & District 14 \\
\hline 6630 & District 15 \\
\hline 6220 & District 16 \\
\hline 7109 & District 17 \\
\hline 4109 & District 18 \\
\hline 4279 & District 19 \\
\hline 2496 & District 20 \\
\hline 4291 & District 21 \\
\hline 1795 & District 22 \\
\hline
\end{tabular}

Based on table2, it can be concluded that the best condition in terms of the proportion of green space density and population, can be seen in district 22 .

\section{Population index for every park}

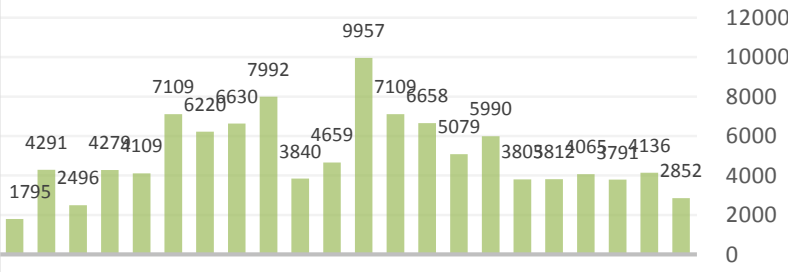

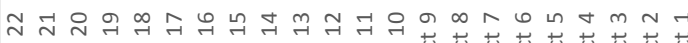

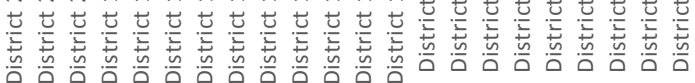

Fig 3. Population index for every park

Table 3 : Green space per capita in comparison with the global standards local standards

\begin{tabular}{|c|c|c|c|}
\hline worldly & In Iran & Real & District \\
\hline 20 & 12 & 16.7 & District 1 \\
\hline 20 & 12 & 17.7 & District 2 \\
\hline 20 & 12 & 14.3 & District 3 \\
\hline 20 & 12 & 7.9 & District 4 \\
\hline 20 & 12 & 16.4 & District 5 \\
\hline 20 & 12 & 11.5 & District 6 \\
\hline 20 & 12 & 3.7 & District 7 \\
\hline 20 & 12 & 4.1 & District 8 \\
\hline 20 & 12 & 5.2 & District 9 \\
\hline 20 & 12 & 1.8 & District 10 \\
\hline 20 & 12 & 4.6 & District 11 \\
\hline
\end{tabular}

\begin{tabular}{|c|c|c|c|}
20 & 12 & 4.9 & District 12 \\
\hline 20 & 12 & 7.6 & District 13 \\
\hline 20 & 12 & 5 & District 14 \\
\hline 20 & 12 & 12.2 & District 15 \\
\hline 20 & 12 & 9.3 & District 16 \\
\hline 20 & 12 & 61.3 & District 17 \\
\hline 20 & 12 & 11.9 & District 18 \\
\hline 20 & 12 & 61.3 & District 19 \\
\hline 20 & 12 & 15.8 & District 20 \\
\hline 20 & 12 & 19 & District 21 \\
\hline 20 & 12 & 33.6 & District 22 \\
\hline
\end{tabular}

Determining green space per capita:

Determining green space per capita and comparing it with global standard is one of the key parameters in assessing green space's conditions.

The following formula is used for the calculation of green space per capita:

$$
\text { green space per capita }=\frac{\text { The size of the green space }}{\text { The population of the district }}
$$

The index determined by the United Nations Environment Programme (UNEP) is 20-25 square meters for every individual. However, defining this standard is much dependent on the geographic conditions of the location under study. For example for a place like Mazandaran Province which is mainly a coastal province, this per capita is different from that of the city of Yazd which has desert and dry climate. On average this per capita in Iran is about 7-12 square meters for every individual.

It must be noted that here by green space per capita it is meant the kind of green space which have been prepared for spending leisure time, playing activities and having fun.

In the following table you can see the per capita for different districts and their comparison with the standard of Iran and the one announced by the United Nations Environment Programme.

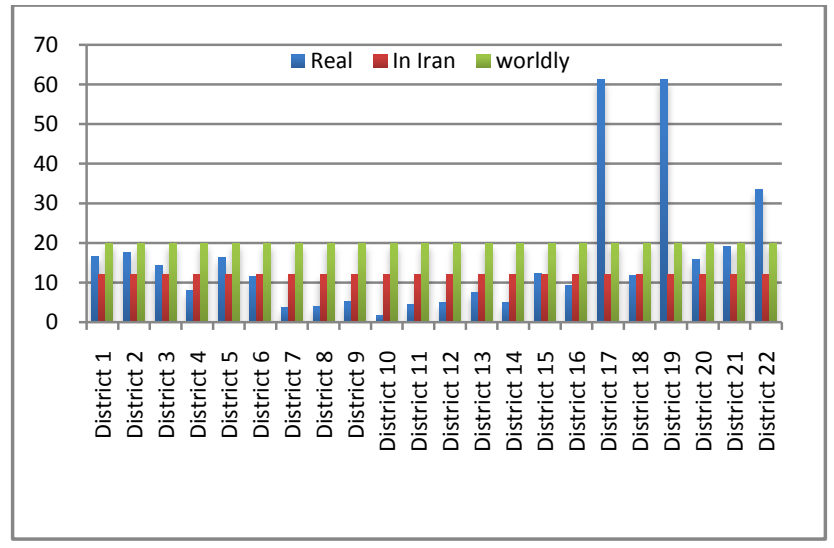

Fig 4: Green space per capita in comparison with the global standards local standards. 
Due to the size of the city of Tehran and the ease of studying, Lavizan Forest Park in district 4 and Sorkheh Hesar Forest Park in district 13 were chosen as the pilot of this research study. In the beginning of the study, the trees in the mentioned parks were of broad-leaf types but through coordination and the help by the Green Space Department of Tehran Municipality, the trees' types of some parts of both forest parks were changed to needle-leaf trees so we can study the effect of the trees types on air pollution and the pollutants.09193222451

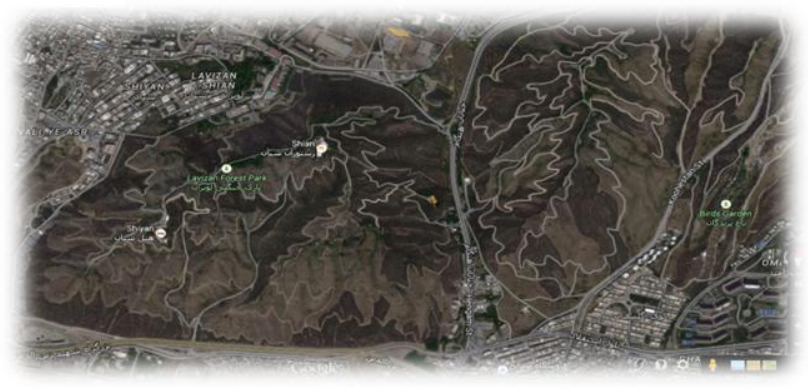

Fig 5: A view of Lavizan Forest Park

In the beginning, the pollutant level of those two forest parks in the certain time limit was assessed. The results indicated the existence of some main pollutants such as sulfur dioxide and nitrogenous oxides in the time limit of 2013 to 2015 determined in the pilot study. They're also shown in the following tables.

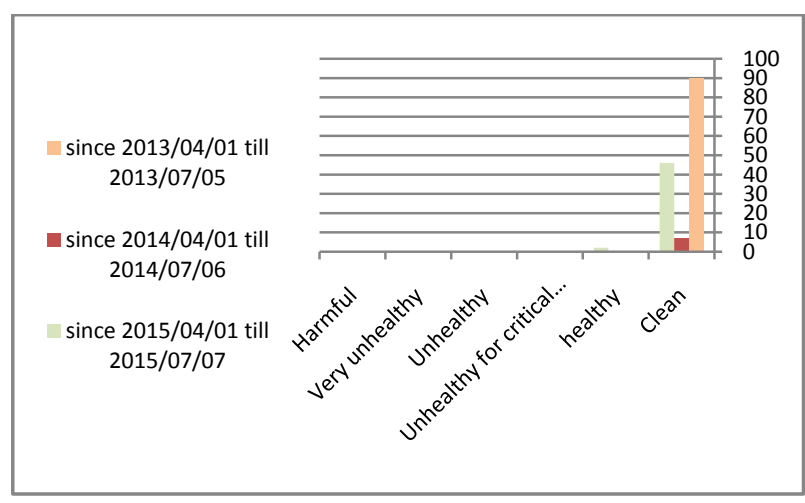

Fig 6: The level of sulfur dioxide (SO2) in Lavizan forest park since 2013 to 2015

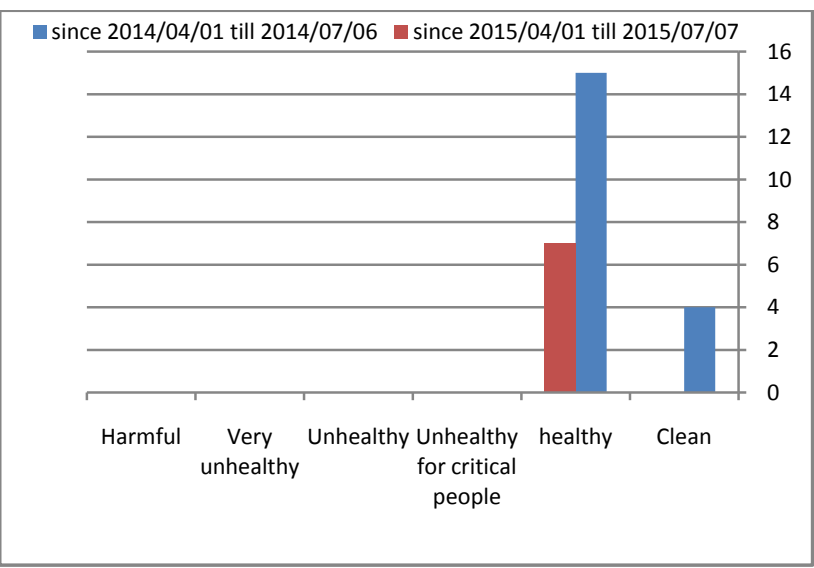

Fig 7: The level of Nitrogen dioxide (NO2) in Sorkheh Hesar forest park since 2013 to 2015

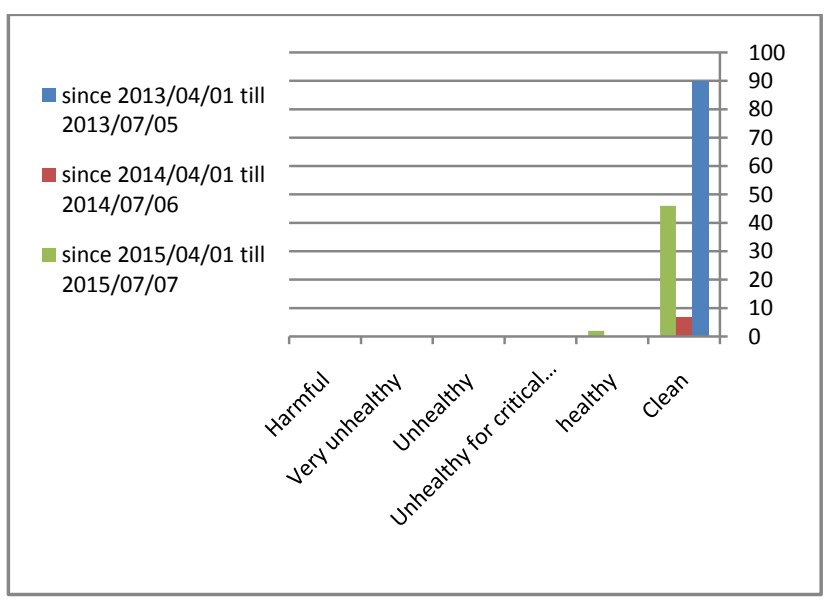

Fig 8: The level of Nitrogen dioxide (NO2) Lavizan forest park since 2013 to 2015

\section{CONCLUSION}

Due to the effect of air pollutants on public health, especially infants, it has been tried in the present study to decrease the amount of these pollutants through some changes. After conducting some preliminary studies, some forest parks in different districts of Tehran (Sorkheh Hesar and Lavizan Forest Park) were chosen as the pilot and the trees types of some parts of them were changed. Before doing that, the density of some main pollutants such as sulfur dioxide and nitrogenous oxides were measured. Having changed the trees types, the amount of the mentioned pollutants were again measured which showed a strikingly high decrease.

In the future, further studies can be conducted to investigate the role of other plants types in absorbing some other pollutants especially carbon dioxide which is considered as a greenhouse gas. The mentioned studies must be in accordance with Tehran's weather condition and also taking account the related economic profits.

\section{ACKNOWLEDGEMENT}

The authors are grateful to the reviewers for their useful suggestions, which highly contributed to improve the readability and the value of the paper.

\section{REFERENCES}

[1] Regina , B. and Asta, D.2015 . Surrounding greenness, proximity to city parks and pregnancy outcomes in Kaunas cohort study .International Journal of Hygiene and environmental Health 218(3), 358-365.

[2] Sarah L , B. and Cassandra ,P.2014 . Green Space ,health and wellbeing: individual agency. Health and place 30, 287-292.

[3] Jenifer R. ,W. and Janson,B.2014 . Urban green space, public health and environmental justice: The challenge of making cities 'just green enough'. Landscape and Urban Planning 125, 234-244.

[4] Payam ,D. and John ,W.2014 . Inequality, green spaces, and pregnant women: Roles of ethnicity and individual and neighborhood socioeconomic status. Environment International 71, 101-108.

[5] Elissa ,H. and Chih-Da ,W. 2014 . Green space and mortality following ischemic stroke. Environmental Research 133, 24-48. 
[6] Mazlina, M. 2014 . Health Issues and Awareness, and the Significant of Green Space for Health Promotion in Malaysia. AMER International Conference on Quality of Life, 153(16), 209-220.

[7] Olivier ,L . and Jun ,W.2013 . Green space and pregnancy outcome in South Claifornia. Health and place 24, 191-195.

[8] Nutsford, D ., and A.L.Pearson.2013 . An ecological study investigating the association between access to urban green space and mental health. Public health 127(11), 1005-1011.

[9] Oliver T,M. and Nick ,T.2012 . Green spaces and physical activity: an observational study using health survey for England data. Health and place 18(5), 1034-
1041.

[10] Payam ,D. and Audrey de ,N.2012 . Green space, health inequality and pregnancy. Environment International 40, 110-115.

[11] Paul j. ,v.2012 . A cohort study relating urban green space with mortality in Ontario,Canada. Environmental research 115, 51-58.

[12] Salehy s.7 et al, n 32.v.2013 .Assess the spatial distribution of urban parks using network analysis. Urban Management, 185-196.

[13] Lotfy s.\& et al ,N.10.v.2014 . Distribution, standards and urban green space per capita is calculated based on Bahram Soltani. Geography and urban planning, 1-18. 